\title{
Synthesis and Luminescence Properties of Lanthanide Complexes of a Novel Polyaminopolycarboxylate Ligand
}

\author{
Chang-quan Tang, Rui-ren Tang, ${ }^{*}$ Chun-hua Tang, and Zhi-wen Zeng
}

\author{
School of Chemistry and Chemical Engineering, Central South University, Hunan, 410083, P. R. China \\ *E-mail: trr@mail.csu.edu.cn
}

Received January 8, 2010, Accepted March 14, 2010

\begin{abstract}
A novel polyaminopolycarboxylate ligand with many coordination sites, $N, N, N^{1}, N^{1}, N^{2}, N^{2}-[(2,4,6$-tri(aminomethyl)pyridine] hexakis(acetic acid) (TPHA), was designed and synthesized and its lanthanide complexes $\mathrm{Na}_{6} \mathrm{~Tb}_{2}\left(\mathrm{TPHA} \mathrm{Cl}_{6}\right.$. $14 \mathrm{H}_{2} \mathrm{O}, \mathrm{Na}_{6} \mathrm{Eu}_{2}$ (TPHA) $\mathrm{Cl}_{6} \cdot 8 \mathrm{H}_{2} \mathrm{O}, \mathrm{Na}_{6} \mathrm{Gd}_{2}$ (TPHA) $\mathrm{Cl}_{6} \cdot 11 \mathrm{H}_{2} \mathrm{O}$ and $\mathrm{Na}_{6} \mathrm{Sm}_{2}$ (TPHA)Cl $\mathrm{Cl}_{6} \cdot 9 \mathrm{H}_{2} \mathrm{O}$ were successfully prepared. The ligand and the complexes were characterized by elemental analysis, IR, mass, NMR and TG-DTA. The TG-DTA studies indicated that the complexes had a high thermal stability, whose initial decomposition temperature was over $270^{\circ} \mathrm{C}$. The luminescence properties of the complexes in solid state were investigated and the results suggested that $\mathrm{Tb}^{3+}$ and $\mathrm{Eu}^{3+}$ ions could be sensitized efficiently by the ligand, especially the $\mathrm{Tb}(\mathrm{III})$ complex displayed a very strong luminescence intensity $(>10000)$ and only displayed characteristic metal-centered luminescence. Also, the correlative comparison between the structure of ligand and luminescence properties showed how the number of the coordination atoms of ligand can be a prominent factor in the effectiveness of ligand-to-metal energy transfer.
\end{abstract}

Key Words: Synthesis, Pyridine, Lanthanide complexes, Luminescence

\section{Introduction}

Lanthanide trivalent cations have excellent photoluminescent properties usable in a high range of different applications. But the ions' poor ability to absorb light makes it necessary to dress them up with an organic ligand as a skin in the form of a complex. ${ }^{1}$ The complexes have become increasingly significant in the last few years due to the wide variety of potential applications in many important areas of chemistry, ${ }^{2-4}$ biology, ${ }^{5-6}$ medicine $^{7-8}$ and imaging. ${ }^{9-12}$

The design of the organic part of such complexes is thus paramount in achieving the required circumstances for the complex to be efficiently luminescent. The ligand needs to incorporate a chromophoric unit (antenna group), for absorbing light and transferring it to the metallic ion, namely, the efficient antenna effect. The usual conditions to be fulfilled are good yields for intersystem crossing and reasonable matching bet- ween the chromophore first triplet state and the accepting levels of the metal. Another important feature is that the organic ligand must also provide good isolation of the metal from the interaction with water molecules, which would otherwise cause nonradiative deactivation of the excited state. ${ }^{13}$ The proton relaxivity of gadolinium complexes is directly correlated to the number of metal-bound water molecules (inner-sphere contribution). ${ }^{14}$ In contrast, inner-sphere water molecules contribute to reduce emission lifetime and quantum yield for $\mathrm{Tb}^{3+}$ and especially $\mathrm{Eu}^{3+}$ luminescence. ${ }^{15}$ And it seems that the ligand with more coordination sites can effectively prevent water molecules participating in coordination with metal ion. The achievement of all these requirements is not an easy task and research in this area is very active.

In this article, we have designed and synthesized a novel ligand (Scheme 1), $N, N, N^{1}, N^{1}, N^{2}, N^{2}$-[( 2,4,6-tri(aminoethyl)pyridine]hexakis(acetic acid)(TPHA), and studied the lumine-

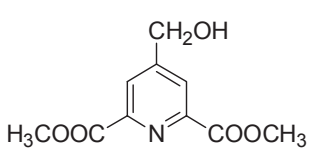

1
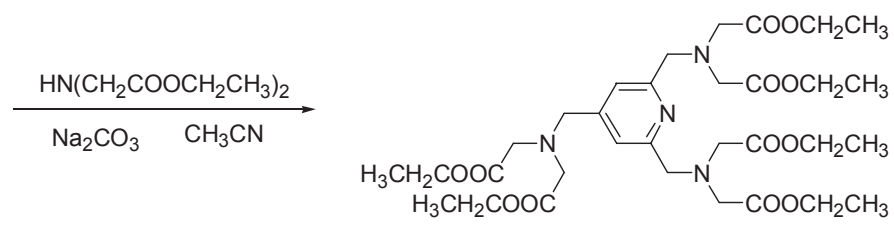<smiles>OCc1cc(CO)nc(CO)c1</smiles>

2

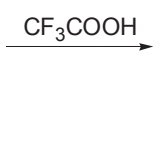<smiles>BrCc1cc(CBr)nc(CBr)c1</smiles>

3<smiles>O=C(O)CN(CC(=O)O)Cc1cc(CN(CC(=O)O)CC(=O)O)nc(CN(CC(=O)O)CC(=O)O)c1</smiles>

TPHA

Scheme 1. Synthetic route of TPHA 
scence properties of its $\mathrm{Tb}(\mathrm{III}), \mathrm{Eu}(\mathrm{III}), \mathrm{Gd}(\mathrm{III})$ and $\mathrm{Sm}(\mathrm{III})$ complexes respectively, in the inner-sphere of which there were none $\mathrm{H}_{2} \mathrm{O}$ molecules, proved by IR and TG-DTA studies and in agreement with the expectation. The ligand contain amine and carboxyl functionalities which known for its capability to bind lanthanide ions via interaction with $\mathrm{C}=\mathrm{O}$ oxygen atoms and amine nitrogen atoms. ${ }^{16}$ This ligand presents three main advantages: (i) its many donor groups prevent coordination of water molecules; (ii) the pyridine ring may act as an efficient antenna in $\mathrm{Ln}^{3+}$ photosensitization; (iii) the tri (iminodiacetate) unit is a very efficient chelating system for $\mathrm{Ln}^{3+}$ ions in aqueous solutions. ${ }^{17}$ The compounds are stable, water soluble and potentially suited as labels for biological applications.

\section{Experimental Section}

Materials and measurements. Rare earth chlorides and 4(hydroxylmethyl)pyridine-2,6-dicarboxylate 1 were prepared as described in the literatures. ${ }^{18}$ Other chemicals were of A.R. grade and used without further purification.

Melting points were determined on a XR-4 apparatus (thermometer uncorrected); elemental analysis was carried out by a PerkinElmer 2400 elemental analyzer; Content of Ln(III) was determined by EDTA titration. Infrared spectra (4000 - 400 $\mathrm{cm}^{-1}$ ) were recorded with samples as $\mathrm{KBr}$ discs using a Nicolet NEXUS 670 FTIR spectrophotometer. UV spectra were recorded on a Varlan UV-vis spectrophotometer. ${ }^{1} \mathrm{H}-\mathrm{NMR}$ was measured with a Bruker-500MHz nuclear magnetic resonance spectrometer with $\mathrm{CDCl}_{3}$ or DMSO as solvent and TMS as internal reference. Mass spectrum was measured using a ZAB-HS analyzer. The excitation and emission spectra were recorded on a Hitich F-4500 luminescence spectrophotometer. Thermal gravimetric (TG) and differential thermal analyses (DTA) were performed in the nitrogen atmosphere using a Netzsch TG209 thermogravimetric analyzer at a heating rate of $10^{\circ} \mathrm{C} \cdot \mathrm{min}^{-1}$ from 30 to $700{ }^{\circ} \mathrm{C}$.

Synthesis of 2,4,6-tri(hydroxylmethyl)pyridine (2): To 100 $\mathrm{mL}$ of dry THF containing $300 \mathrm{mg} \mathrm{LiBH}_{4}$ was added $1.0 \mathrm{~g}$ (4.4 mmol) of 1 . After stirring for $3.5 \mathrm{~h}$ at room temperature, $0.6 \mathrm{~mL}$ of water, $0.6 \mathrm{~mL}$ of $15 \% \mathrm{NaOH}$, and $1.5 \mathrm{~mL}$ of water were added dropwise to the solution. The solution was filtered to remove precipitate, and the solvent was evaporated. The product was recrystallized with $\mathrm{CH}_{3} \mathrm{CN}$ and then dried. A white powder of 2 was obtained $(0.66 \mathrm{~g}, 76.6 \%$ yield $)$; mp $116-118^{\circ} \mathrm{C}$. Anal. Calcd for $\mathrm{C}_{8} \mathrm{H}_{11} \mathrm{NO}_{3}(\%)$ : C, 56.80; H, 6.51; N, 8.28. Found: C, 56.72; H, 6.54; N, 8.31. IR (KBr), v/ $\mathrm{cm}^{-1}: 3351,2927$, $2851,1613,1568,1424 .{ }^{1} \mathrm{H} \mathrm{NMR}\left(\mathrm{CDCl}_{3}\right) \delta_{\mathrm{H}} 7.92(2 \mathrm{H}, \mathrm{s}, \mathrm{ArH})$, $5.29\left(4 \mathrm{H}, \mathrm{s}, \mathrm{CH}_{2}\right), 4.83\left(2 \mathrm{H}, \mathrm{s}, \mathrm{CH}_{2}\right), 4.67(3 \mathrm{H}, \mathrm{t}, J=5.8 \mathrm{~Hz}, \mathrm{OH})$.

Synthesis of 2,4,6-tri(bromomethyl)pyridine (3): To $8 \mathrm{~mL}$ of $40 \% \mathrm{HBr}$ containing $1 \mathrm{~g}$ of 2 (5.92 $\mathrm{mmol})$ was added drop- wise $15 \mathrm{~mL}$ of $\left(\mathrm{CH}_{3} \mathrm{CO}\right)_{2} \mathrm{O}$, and the solution was refluxed for $24 \mathrm{~h}$ with stirring. After the solvent was evaporated, the residue was dissolved in $30 \mathrm{~mL}$ of $\mathrm{CH}_{2} \mathrm{Cl}_{2}$ and then washed with $10 \%$ $\mathrm{Na}_{2} \mathrm{CO}_{3}$. The crude product was then extracted from the aqueous phase with $3 \times 20 \mathrm{~mL}$ portions of $\mathrm{CH}_{2} \mathrm{Cl}_{2}$. The organic phase were combined, dried over $\mathrm{MgSO}_{4}$, and evaporated to dryness in vacuum, affording $1.21 \mathrm{~g}$ of pure compound 3 in $57.1 \%$ yield; mp 61 - $63{ }^{\circ} \mathrm{C}$. EI-MS, $m / z 358\left(\mathrm{M}^{+}, 6 \%\right), 278$ ([M - Br $\left.]^{+}, 100 \%\right)$, $198\left([\mathrm{M}-2 \mathrm{Br}]^{+}, 13 \%\right), 118\left([\mathrm{M}-3 \mathrm{Br}]^{+}, 15 \%\right)$. Anal. Calcd for $\mathrm{C}_{8} \mathrm{H}_{8} \mathrm{NBr}_{3}(\%)$ : C, 26.82; H, 2.23; N, 3.91. Found: C, 26.77; $\mathrm{H}, 2.26$; N, 3.87. IR (KBr), $v / \mathrm{cm}^{-1}: 3036,2962,1601,1561$, 1431, 597. ${ }^{1} \mathrm{H} \mathrm{NMR}\left(\mathrm{CDCl}_{3}\right) \delta_{\mathrm{H}} 7.31(2 \mathrm{H}, \mathrm{s}, \mathrm{ArH}), 4.67(4 \mathrm{H}, \mathrm{s}$, $\left.\mathrm{CH}_{2}\right), 4.23\left(2 \mathrm{H}, \mathrm{s}, \mathrm{CH}_{2}\right)$.

\section{Synthesis of hexaethyl.}

$N, N, N^{1}, N^{1}, N^{2}, N^{2}-[(2,4,6$-tri(aminoethyl)-pyridine]hexakis (acetate) (4): To a solution of $20 \mathrm{~mL}$ of dry $\mathrm{CH}_{3} \mathrm{CN}$ containing $0.286 \mathrm{~g}$ of $\mathbf{3}(0.8 \mathrm{mmol}), 453 \mathrm{mg}$ of diethyl iminodiacetate $(2.4$ mmol) and $0.6 \mathrm{~g}$ of $\mathrm{Na}_{2} \mathrm{CO}_{3}$ were added. The mixture was refluxed for $24 \mathrm{~h}$ with stirring. After filtering, the solvent was evaporated. The residue was dissolved in $20 \mathrm{~mL}$ of $\mathrm{CHCl}_{3}$, and then the solution was washed with $2 \times 20 \mathrm{~mL}$ of water. After the organic phase was dried with $\mathrm{Mg}_{2} \mathrm{SO}_{4}$, the solvent was evaporated. The oily residue was purified by silica gel column chromatography using ethyl acetate as eluent to yield $0.42 \mathrm{~g}(76.9 \%$ yield) of 4. Anal. Calcd for $\mathrm{C}_{32} \mathrm{H}_{50} \mathrm{~N}_{4} \mathrm{O}_{12}$ (\%): C, 56.30; $\mathrm{H}$, 7.33; N, 8.21. Found: C, 56.38; H, 7.29; N, 8.23. ESI ${ }^{+} \mathrm{MS}, \mathrm{m} / z$ $683\left([\mathrm{M}+\mathrm{H}]^{+}, 100 \%\right), 705\left([\mathrm{M}+\mathrm{Na}]^{+}, 26 \%\right)$. IR $(\mathrm{KBr}), v / \mathrm{cm}^{-1}$ : 2982, 2936, 1737, 1605, 1567, 1446, 1419, 1371, 1194, 1153, 1030. ${ }^{1} \mathrm{H} \mathrm{NMR}\left(\mathrm{CDCl}_{3}\right) \delta_{\mathrm{H}} 7.48(2 \mathrm{H}, \mathrm{s}, \mathrm{ArH}), 4.16(12 \mathrm{H}, \mathrm{q}, J=$ $\left.7.2 \mathrm{~Hz}, \mathrm{OCH}_{2}\right), 4.06\left(4 \mathrm{H}, \mathrm{s}, \operatorname{Ar}(2,6) \mathrm{CH}_{2}\right), 3.97(2 \mathrm{H}, \mathrm{s}, \operatorname{Ar}(4)$ $\left.\mathrm{CH}_{2}\right), 3.62\left(8 \mathrm{H}, \mathrm{s}, \mathrm{CH}_{2}\right), 3.55\left(4 \mathrm{H}, \mathrm{s}, \mathrm{CH}_{2}\right), 1.26(18 \mathrm{H}, \mathrm{t}, J=$ $7.2 \mathrm{~Hz}, \mathrm{CH}_{3}$ ).

Synthesis of $N, N, N^{1}, N^{1}, N^{2}, N^{2}-[(2,4,6$-tri(aminoethyl)-pyridine]hexakis(acetic acid) (TPHA): A solution of 4 (457 mg, $0.67 \mathrm{mmol})$ in $\mathrm{CF}_{3} \mathrm{COOH}(8 \mathrm{~mL})$ was stirred for $12 \mathrm{~h}$ at $\mathrm{rt}$. After evaporation, an oily residue was obtained (344 mg, 100\% yield). Anal. Calcd for $\mathrm{C}_{20} \mathrm{H}_{26} \mathrm{~N}_{4} \mathrm{O}_{12}(\%)$ : C, 46.69; H, 5.06; N, 10.89. Found: C, 46.61; H, 4.93; N, 10.96. IR (KBr), v/cm ${ }^{-1}$ : $3475,2991,1746,1672,1543,1407,1211,1171,930 .{ }^{1} \mathrm{H}$ NMR $\left(\mathrm{DMSO}-d_{6}\right) \delta_{\mathrm{H}} 7.67(2 \mathrm{H}, \mathrm{s}, \mathrm{ArH}), 3.98\left(4 \mathrm{H}, \mathrm{s}, \operatorname{Ar}(2,6) \mathrm{CH}_{2}\right)$, $3.91\left(2 \mathrm{H}, \mathrm{s}, \mathrm{Ar}(4) \mathrm{CH}_{2}\right), 3.56\left(8 \mathrm{H}, \mathrm{s}, \mathrm{CH}_{2}\right), 3.53\left(4 \mathrm{H}, \mathrm{s}, \mathrm{CH}_{2}\right)$.

Synthesis of the complexes. An solution of $\mathrm{LnCl}_{3}(\mathrm{Ln}=\mathrm{Tb}$, $\mathrm{Eu}, \mathrm{Gd}$ and $\mathrm{Sm})(0.4 \mathrm{mmol})$ in ethanol $(6 \mathrm{~mL})$ was added dropwise to a solution of the ligand $(0.4 \mathrm{mmol})$ in ethanol $(4 \mathrm{~mL})$ and the mixture stirred at $60{ }^{\circ} \mathrm{C}$ for $8 \mathrm{~h}$. The $\mathrm{pH}$ value of the solution was adjusted to 6.0 by dropwise addition of aqueous $\mathrm{NaOH}\left(0.01 \mathrm{~mol} \cdot \mathrm{L}^{-1}\right)$. The resulting precipitate was collected by filtration, washed three times each with ethanol and chloroform mixture $(1: 1, \mathrm{v}: \mathrm{v})$ and dried in vacuum to give a flake solid. The results of elemental analysis (see Table 1) indicated

Table 1. Elemental analytical data for the complexes

\begin{tabular}{ccccc}
\hline Complex & Ln (\%) found (calc.) & C (\%) found (calc.) & H (\%) found (calc.) & N (\%) found (calc.) \\
\hline $\mathrm{Na}_{6} \mathrm{~Tb}_{2}$ (TPHA)Cl ${ }_{6} \cdot 14 \mathrm{H}_{2} \mathrm{O}$ & $22.11(22.16)$ & $16.79(16.72)$ & $3.74(3.76)$ & $3.94(3.90)$ \\
$\mathrm{Na}_{6} \mathrm{Eu}_{2}$ (TPHA) $\mathrm{Cl}_{6} \cdot 8 \mathrm{H}_{2} \mathrm{O}$ & $23.18(23.15)$ & $18.25(18.28)$ & $3.17(3.20)$ & $4.30(4.27)$ \\
$\mathrm{Na}_{6} \mathrm{Gd}_{2}$ (TPHA)Cl $611 \mathrm{H}_{2} \mathrm{O}$ & $22.77(22.80)$ & $17.48(17.43)$ & $3.52(3.49)$ & $4.03(4.07)$ \\
$\mathrm{Na}_{6} \mathrm{Sm}_{2}$ (TPHA)Cl $6.9 \mathrm{H}_{2} \mathrm{O}$ & $22.54(22.61)$ & $18.12(18.09)$ & $3.29(3.32)$ & $4.25(4.22)$ \\
\hline
\end{tabular}


that the composition of the complexes conforms to be $\mathrm{Na}_{6} \mathrm{~Tb}_{2}$ (TPHA) $\mathrm{Cl}_{6} \cdot 14 \mathrm{H}_{2} \mathrm{O}, \mathrm{Na}_{6} \mathrm{Eu}_{2}$ (TPHA) $\mathrm{Cl}_{6} \cdot 8 \mathrm{H}_{2} \mathrm{O}, \mathrm{Na}_{6} \mathrm{Gd}_{2}$ (TPHA) $\mathrm{Cl}_{6} \cdot 11 \mathrm{H}_{2} \mathrm{O}$ and $\mathrm{Na}_{6} \mathrm{Sm}_{2}$ (TPHA) $\mathrm{Cl}_{6} \cdot 9 \mathrm{H}_{2} \mathrm{O}$. Generally, polyaminopolycarboxylate ligand should possibly lead to oligomeric typed complexes, however, the ligand synthesized by us has many coordination sites, so it has enough capability to accept two ions. We suspect that the chemical structure of complexes may be like this:

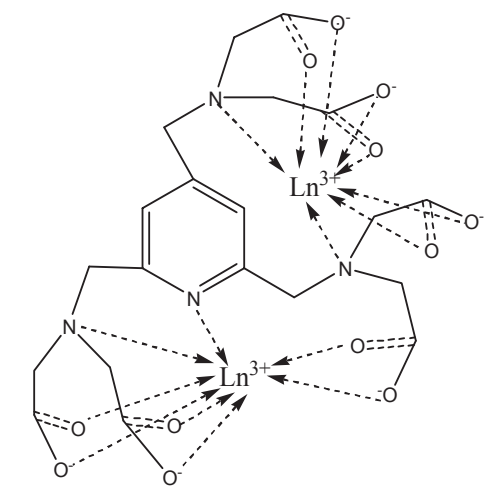

The chemical structure of the complexes.

\section{Results and Discussion}

IR spectra of the complexes. The IR spectra of the four complexes are similar (Figure 1-4), indicating that they are structurally alike. Table 2 summarizes the characteristic bands observed for the ligand and its metal complexes. The IR spectra of the free ligand shows bands at 3478, 1748 and $1663 \mathrm{~cm}^{-1}$, which can be assigned as $v(\mathrm{C}-\mathrm{OH}), v(\mathrm{C}=\mathrm{O})$ and $v(\mathrm{C}=\mathrm{N})$ of the ligand, respectively. In the complexes, the band for $v(\mathrm{C}=\mathrm{N})$ of pyridine ring shows a shift to a lower frequency (1410 - 1435 $\mathrm{cm}^{-1}$ ) as a result of the coordination through metal-nitrogen bond. The bands $v(\mathrm{C}=\mathrm{O})$ at $1748 \mathrm{~cm}^{-1}$ in free ligands disappear and new bands appear at $1575-1592 \mathrm{~cm}^{-1}$ and $1325-1364 \mathrm{~cm}^{-1}$ assignable to $\left[v_{a s}\left(\mathrm{COO}^{-}\right)+v_{\mathrm{s}}\left(\mathrm{COO}^{-}\right)\right]$. In each case, the remarkable shifts suggested that the relevant oxygen and nitrogen atoms of the ligand were involved in coordination to the metal centre and the ligand had a strong capability of coordination. The absorption bands assigned to the $v(\mathrm{Ln}-\mathrm{O})$ and $v(\mathrm{Ln}-\mathrm{N})$ stretching frequencies of the complex were observed at 427 $453 \mathrm{~cm}^{-1}$ and $556-594 \mathrm{~cm}^{-1}$ respectively, also confirmed that the oxygen and nitrogen atoms participated in the coordination. The bands $v(\mathrm{OH})$ centered at about $3400 \mathrm{~cm}^{-1}$ are always relatively intense and can be attributed to solvated water. The $\rho_{\gamma}\left(\mathrm{H}_{2} \mathrm{O}\right)$ and $\rho_{\omega}\left(\mathrm{H}_{2} \mathrm{O}\right)$ bands usually at approximately $850 \mathrm{~cm}^{-1}$

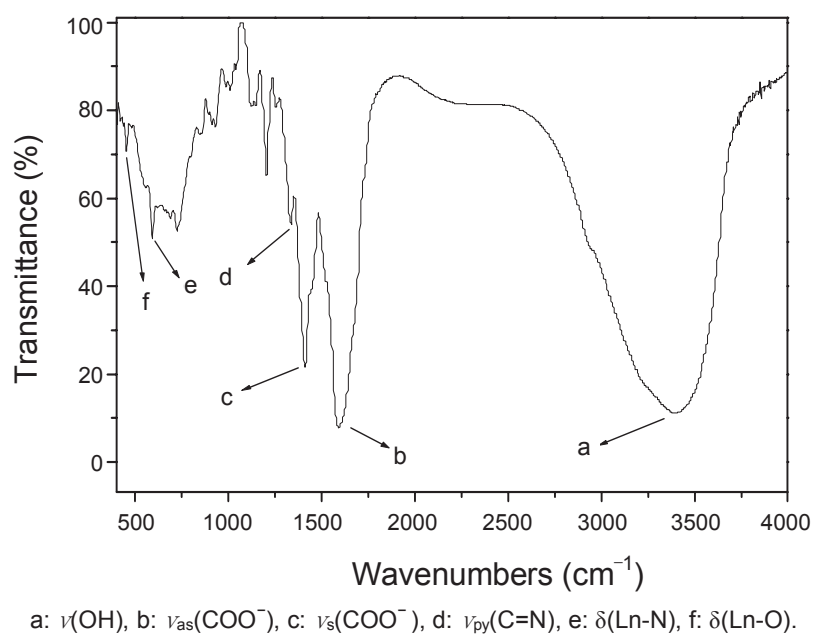

Figure 1. The IR spectrum of Tb (III) complex.

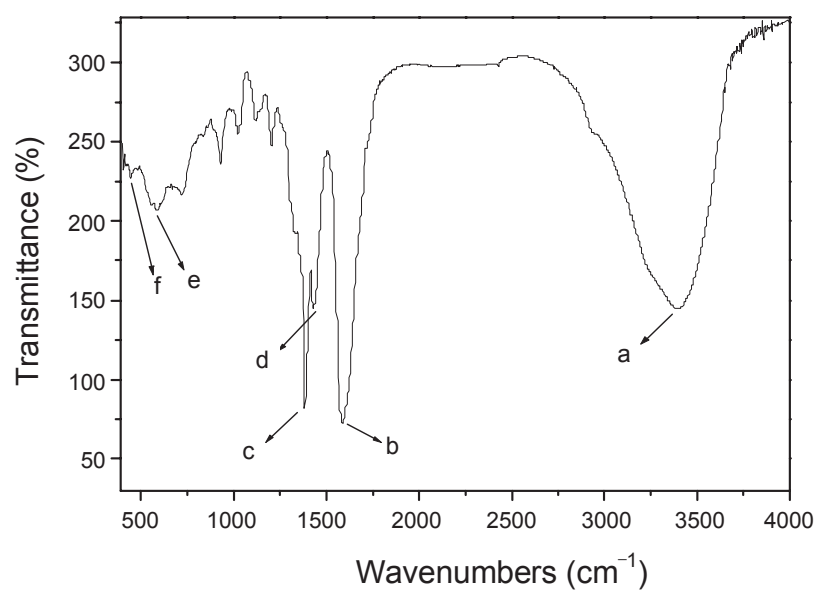

Figure 2. The IR spectrum of Eu(III) complex.

and $650 \mathrm{~cm}^{-1}$ respectively were not observed in the spectra of the complexes, indicating that there are none coordinated water molecules in the inner-sphere of the metal, in agreement with the expectation and proved by TG-DTA studies infra. ${ }^{19}$

Thermal analysis. In order to examine the thermal stability of the complexes and confirm the fact that none water molecules participated in the coordination, the two complexes $\mathrm{Na}_{6} \mathrm{~Tb}_{2}$ (TPHA) $\mathrm{Cl}_{6} \cdot 14 \mathrm{H}_{2} \mathrm{O}$ and $\mathrm{Na}_{6} \mathrm{Eu}_{2}$ (TPHA) $\mathrm{Cl}_{6} \cdot 8 \mathrm{H}_{2} \mathrm{O}$ were selected to perform thermal gravimetric (TG) and differential thermal analyses(DTA). Figure 5 and 6 show the TG-DTA curves of the

Table 2. Characteristic IR bands $\left(\mathrm{cm}^{-1}\right)$ of the ligand and its complexes

\begin{tabular}{cccccccc}
\hline Sample & $v(\mathrm{OH})$ & $v(\mathrm{C}=\mathrm{O})$ & $v_{\text {as }}\left(\mathrm{COO}^{-}\right)$ & $v_{\mathrm{s}}\left(\mathrm{COO}^{-}\right)$ & $v_{\text {py }}(\mathrm{C}=\mathrm{N})$ & $\delta(\operatorname{Ln}-\mathrm{N})$ & $\delta(\operatorname{Ln}-\mathrm{O})$ \\
\hline TPHA & 3478 & 1748 & & & 1663 & & \\
$\mathrm{Na}_{6} \mathrm{~Tb}_{2}$ (TPHA) $\mathrm{Cl}_{6} \cdot 14 \mathrm{H}_{2} \mathrm{O}$ & 3393 & & 1592 & 1338 & 1410 & 594 & 453 \\
$\mathrm{Na}_{6} \mathrm{Eu}_{2}$ (TPHA) $\mathrm{Cl}_{6} \cdot 8 \mathrm{H}_{2} \mathrm{O}$ & 3397 & & 1586 & 1364 & 1435 & 587 & 446 \\
$\mathrm{Na}_{6} \mathrm{Gd}_{2}$ (TPHA)Cl $6 \mathrm{Cl}_{6} \cdot 11 \mathrm{H}_{2} \mathrm{O}$ & 3411 & & 1591 & 1325 & 1414 & 556 & 432 \\
$\mathrm{Na}_{6} \mathrm{Sm}_{2}$ (TPHA) $\mathrm{Cl}_{6} \cdot 9 \mathrm{H}_{2} \mathrm{O}$ & 3423 & & 1575 & 1326 & 1413 & 558 & 427 \\
\hline
\end{tabular}

$v_{\text {as }}$, asymmetric; $v_{\mathrm{s}}$, symmetric. 
Table 3. TG-DTA data of $\mathrm{Na}_{6} \mathrm{~Tb}_{2}(\mathrm{TPHA}) \mathrm{Cl}_{6} \cdot 14 \mathrm{H}_{2} \mathrm{O}$ and $\mathrm{Na}_{3} \mathrm{Eu}_{2}(\mathrm{TPHA}) \mathrm{Cl}_{3} \cdot 8 \mathrm{H}_{2} \mathrm{O}$

\begin{tabular}{cccccc}
\hline Complex & Stage & $\begin{array}{c}\text { Temperature range } \\
\left({ }^{\circ} \mathrm{C}\right)\end{array}$ & $\begin{array}{c}\text { DTA peak temperature } \\
\left({ }^{\circ} \mathrm{C}\right)\end{array}$ & $\begin{array}{c}\text { Mass loss rate (\%) found } \\
(\text { calc. })\end{array}$ & $\begin{array}{c}\text { Probable lost } \\
\text { molecules }\end{array}$ \\
\hline $\mathrm{Na}_{6} \mathrm{~Tb}_{2}$ (TPHA) $\mathrm{Tl}_{6} \cdot 14 \mathrm{H}_{2} \mathrm{O}$ & I & $70-150$ & 101 & $16.74(16.80)$ & $14 \mathrm{H}_{2} \mathrm{O}$ \\
& II & $310-350$ & 370 & $35.51(35.57)$ & TPHA \\
$\mathrm{Na}_{6} \mathrm{Eu}_{2}$ (TPHA) $\mathrm{Cl}_{6} \cdot 8 \mathrm{H}_{2} \mathrm{O}$ & I & $65-130$ & 81 & $10.93(11.02)$ & $8 \mathrm{H}_{2} \mathrm{O}$ \\
& II & $270-550$ & 278 & $38.76(38.87)$ & TPHA \\
\hline
\end{tabular}

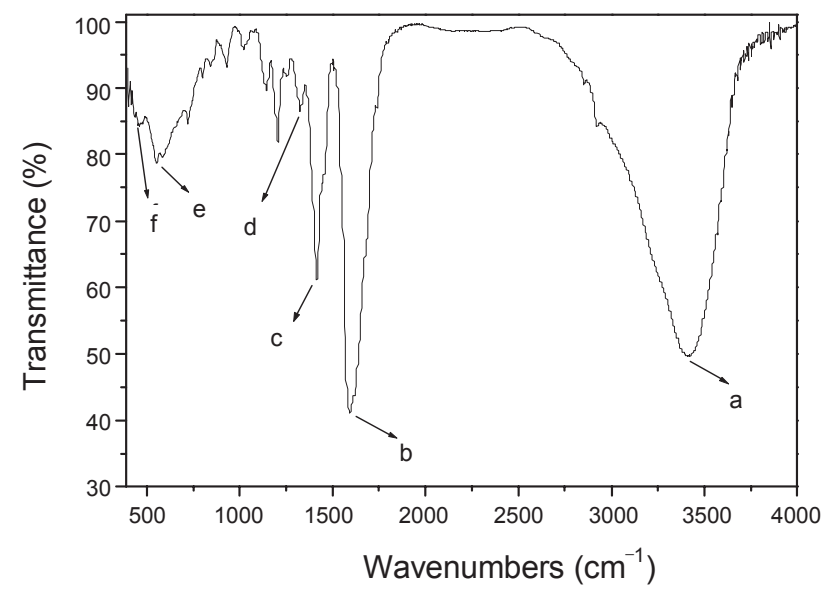

Figure 3. The IR spectrum of Gd(III) complex.

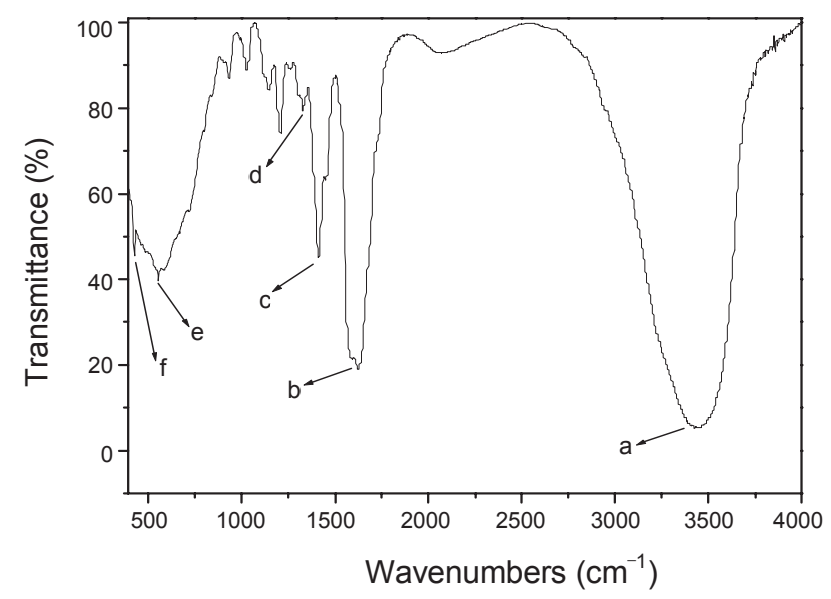

Figure 4. The IR spectrum of Sm(III) complex.

Table 4. Luminescence data for the complexes

\begin{tabular}{|c|c|c|c|c|}
\hline Complexes & $\begin{array}{c}\lambda_{\mathrm{ex}} \\
(\mathrm{nm})\end{array}$ & $\begin{array}{c}\lambda_{\mathrm{em}} \\
(\mathrm{nm})\end{array}$ & LI & Assignment \\
\hline ТРНА & 326 & 438 & 113 & \\
\hline \multirow[t]{4}{*}{$\mathrm{Na}_{6} \mathrm{~Tb}_{2}(\mathrm{TPHA}) \mathrm{Cl}_{6} \cdot 14 \mathrm{H}_{2} \mathrm{O}$} & 276 & 489 & 979 & ${ }^{5} \mathrm{D}_{4}{ }^{-7} \mathrm{~F}_{6}$ \\
\hline & & 543 & 2014 & ${ }^{5} \mathrm{D}_{4}{ }^{7} \mathrm{~F}_{5}$ \\
\hline & & 583 & 232 & ${ }^{5} \mathrm{D}_{4}{ }^{7} \mathrm{~F}_{4}$ \\
\hline & & 619 & 84 & ${ }^{5} \mathrm{D}_{4}{ }^{7} \mathrm{~F}_{3}$ \\
\hline \multirow[t]{2}{*}{$\mathrm{Na}_{6} \mathrm{Eu}_{2}(\mathrm{TPHA}) \mathrm{Cl}_{6} \cdot 8 \mathrm{H}_{2} \mathrm{O}$} & 278 & 590 & 965 & ${ }^{5} \mathrm{D}_{0}{ }^{7} \mathrm{~F}_{1}$ \\
\hline & & 613 & 1834 & ${ }^{5} \mathrm{D}_{0^{-}}{ }^{7} \mathrm{~F}_{2}$ \\
\hline $\mathrm{Na}_{6} \mathrm{Gd}_{2}(\mathrm{TPHA}) \mathrm{Cl}_{6} \cdot 11 \mathrm{H}_{2} \mathrm{O}$ & 325 & 392 & 7720 & \\
\hline $\mathrm{Na}_{6} \mathrm{Sm}_{2}$ (TPHA) $\mathrm{Cl}_{6} \cdot 9 \mathrm{H}_{2} \mathrm{O}$ & 248 & 396 & 2161 & \\
\hline
\end{tabular}

two complexes and some thermal analytical data are listed in Table 3. In the TG-DTG curves, there are two main successive mass loss stages. The first mass loss stage of $\mathrm{Tb}(\mathrm{III})$ and $\mathrm{Eu}(\mathrm{III})$ ion complexes take place between $70-150{ }^{\circ} \mathrm{C}$ and $65-130{ }^{\circ} \mathrm{C}$ with mass loss percentage of $16.74 \%$ and $10.93 \%$ respectively, which corresponds to the release of solvated water content and roughly coincides with the calculated value $\left(14 \mathrm{H}_{2} \mathrm{O}(16.80 \%)\right.$ for $\mathrm{Tb}$ and $8 \mathrm{H}_{2} \mathrm{O}(11.02 \%$ ) for Eu complex). The relatively low decomposition temperatures indicate that the water in the complexes is solvated water rather than coordinated water, for the coordinated water of similar complexes releases commonly above $200{ }^{\circ} \mathrm{C} .{ }^{20-21}$ The second stage in region of $310-500{ }^{\circ} \mathrm{C}$ and $270-550{ }^{\circ} \mathrm{C}$ is attributed to elimination and/or decomposition of TPHA, with mass loss percentage of $35.51 \%$ and $38.76 \%$ respectively, also coincided with the calculated value $(35.57 \%$ and $38.87 \%$ ). These above suggest that the complexes have the relatively high thermal stability and their composition were reasonable.

Luminescence properties of complexes. The luminescence data for each complex were determined in the solid state at room temperature. The width of emission slit and excitation slit of the $\mathrm{Tb}$ (III) complex was $2.5 \mathrm{~nm}$ and the others were 5.0 $\mathrm{nm}$, the voltage of photomultiplier tube was $700 \mathrm{~V}$. The maximum excitation wavelengths $\left(\lambda_{\mathrm{ex}}\right)$ of the ligand, $\mathrm{Tb}(\mathrm{III}), \mathrm{Eu}(\mathrm{III})$, Gd(III) and Sm(III) complexes were 326, 276, 278, 325 and $248 \mathrm{~nm}$, respectively (see Table 4). The difference between the excitation wavelengths for the ligand and the complexes may be resulted from these: firstly, the states of the ligand (oil) and the complexes (solid) are different; secondly, the ligand was coordinated to the rare earth ions in the complexes, its structure and energy state may be changed due to the affection of the metal ions. Obviously, the $\mathrm{CO}_{2} \mathrm{H}$ was converted to $\mathrm{CO}_{2}{ }_{2}^{-}$in the complexes. While the $\lambda_{\text {ex }}$ of the $\mathrm{Tb}$ (III) and Eu(III) complexes of $N, N, N^{1}, N^{1}$-[(2,6-bis(aminoethyl)-pyridine]tetrakis(acetic acid) with only seven donor groups, respectively, were 267 and $265 \mathrm{~nm}$ reported by Veli-Matti Mukkala, ${ }^{22}$ it was not difficult to find that both of the $\lambda_{\mathrm{ex}}$ of $\mathrm{Tb}(\mathrm{III})$ and $\mathrm{Eu}(\mathrm{III})$ complexes reported by us were shifted to longer wavelength. It can be explained that the increase of the number of the coordination atoms causes the energy transitions from ligand to metal ion to be more effectively, because it shields the lanthanide ion from the interaction with $\mathrm{H}_{2} \mathrm{O}$ molecules, which would otherwise cause nonradiative deactivation of the excited state.

Luminescence spectra for the ligand (TPHA) and the complexes were given (Figures 7-11). At $5.0 \mathrm{~nm}$, the luminescence intensity (the maximum peak) observed from the ligand, Eu(III), Gd(III) and Sm(III) complexes were very weak $(113,1834,7720$ and 2161 respectively), while very strong from the $\mathrm{Tb}(\mathrm{III})$ com- 


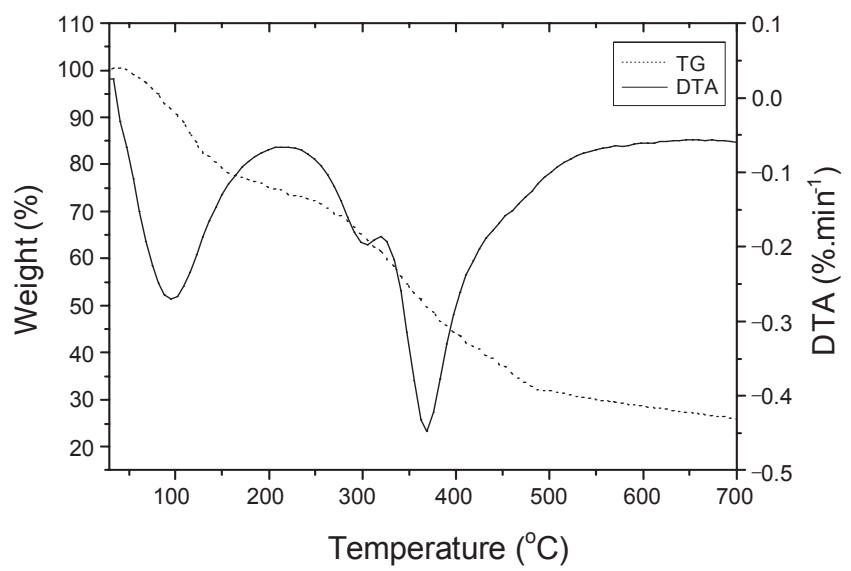

Figure 5. TG and DTA curves for original Tb(III) complex.

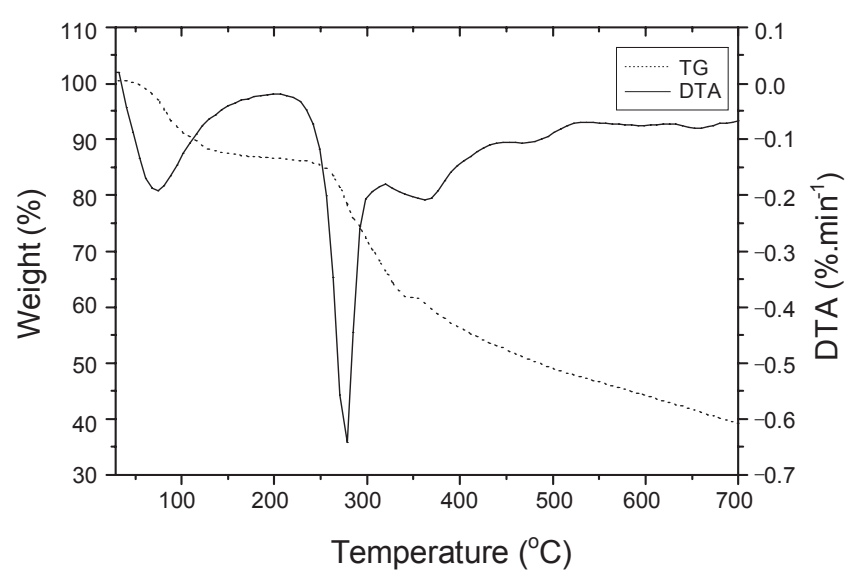

Figure 6. TG and DTA curves for original $\mathrm{Eu}(\mathrm{III})$ complex.

plex $(>10000)$ (spectrum not shown) under the same experimental conditions. It appears that the energy-transfer from the organic ligand (HTPA) to the central $\mathrm{Tb}$ (III) ions is much more effective compared to the other Ln(III) ions. The luminescence spectrum of the ligand was very broad (400 - $550 \mathrm{~nm})$. On the contrary, the $\mathrm{Tb}(\mathrm{III})$ and $\mathrm{Eu}(\mathrm{III})$ complexes possessed narrow emission bands and a large difference between the excitation and emission wavelengths, indicating that the ligand is a comparative good organic chelator to absorb energy and transfer it to $\mathrm{Tb}(\mathrm{III})$ and $\mathrm{Eu}(\mathrm{III})$ ions. However, the Gd(III) and $\mathrm{Sm}(\mathrm{III})$ complexes showed broad emission bands (350 - $470 \mathrm{~nm}$ and 350 - $550 \mathrm{~nm}$ respectively) and the luminescence spectra of them were similar to that of the ligand, indicating that they were attributed to the emission from the ligand, since the luminescence spectra of $\mathrm{Ln}(\mathrm{III})$ are very sharp. The ${ }^{5} \mathrm{D}_{4}{ }^{7} \mathrm{~F}_{5}$ peak of $\mathrm{Tb}$ (III) complex is sharp and strong, showing higher color purity and emission intensity. ${ }^{23}$ The comparison between the luminescence spectra of the ligand and the $\operatorname{Ln}(\mathrm{III})$ complexes indicates that the observed luminescence of $\mathrm{Tb}(\mathrm{III})$ and $\mathrm{Eu}(\mathrm{III})$ complexes with TPHA is associated with the charge transfer from pyridine to the lanthanide ions. The reasons are: firstly, the excitation energies of the $\mathrm{Tb}$ (III) $\left(\lambda_{\text {exn }}=276 \mathrm{~nm}\right)$, the $\mathrm{Eu}(\mathrm{III})\left(\lambda_{\mathrm{exn}}=278\right.$ $\mathrm{nm})$ and the $\mathrm{Sm}(\mathrm{III})\left(\lambda_{\mathrm{exn}}=248 \mathrm{~nm}\right)$ complexes are much higher

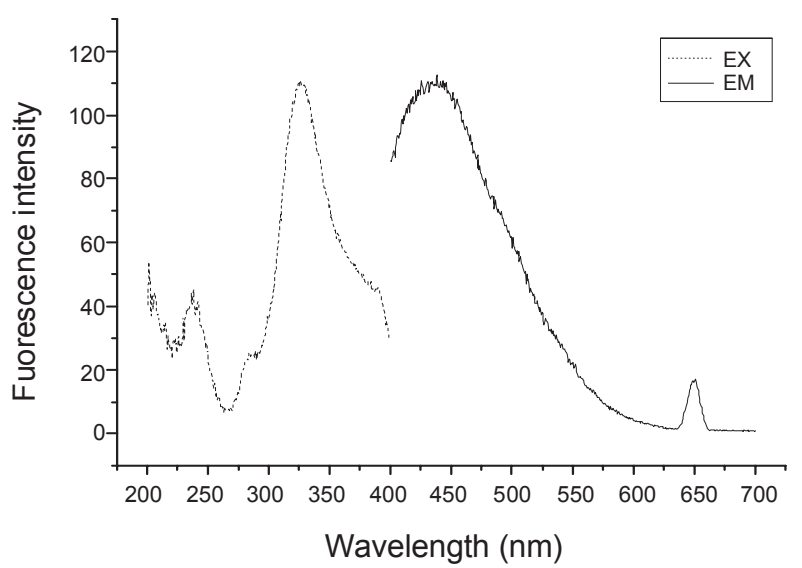

Figure 7. The excitation and emission spectrum of the ligand..

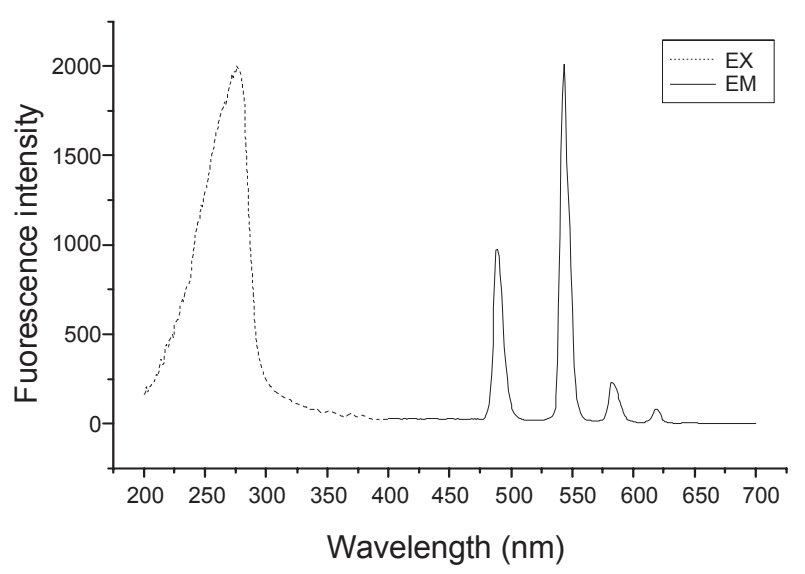

Figure 8. The excitation and emission spectrum of the $\mathrm{Tb}$ (III) complex.

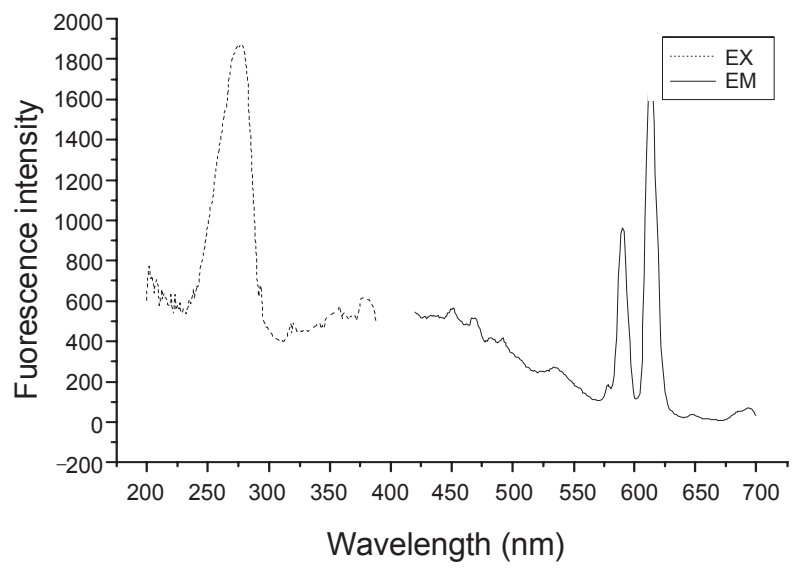

Figure 9. The excitation and emission spectrum of the Eu(III) complex.

than those of the ligand $\left(\lambda_{\text {exn }}=326 \mathrm{~nm}\right)$ and the Gd(III) complex $\left(\lambda_{\text {exn }}=325 \mathrm{~nm}\right)$. Figures 7 and 10 illustrate that the 276 and $278 \mathrm{~nm}$ excitations cannot produce the emission from the ligand. Therefore, these excitations are unable to afford the energy transfer from the ligand to the Ln(III) ions. Secondly, the observed optical properties of the Gd(III) complex are identical to those 


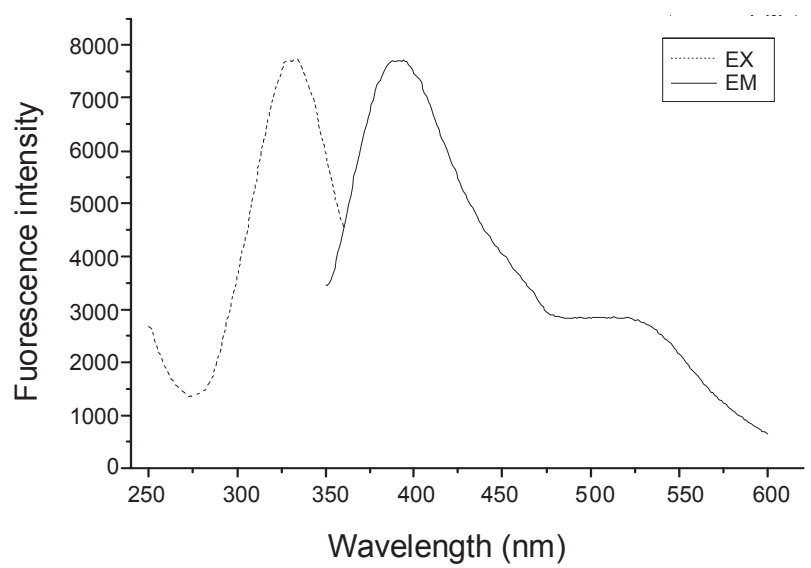

Figure 10. The excitation and emission spectrum of the Gd(III) complex.

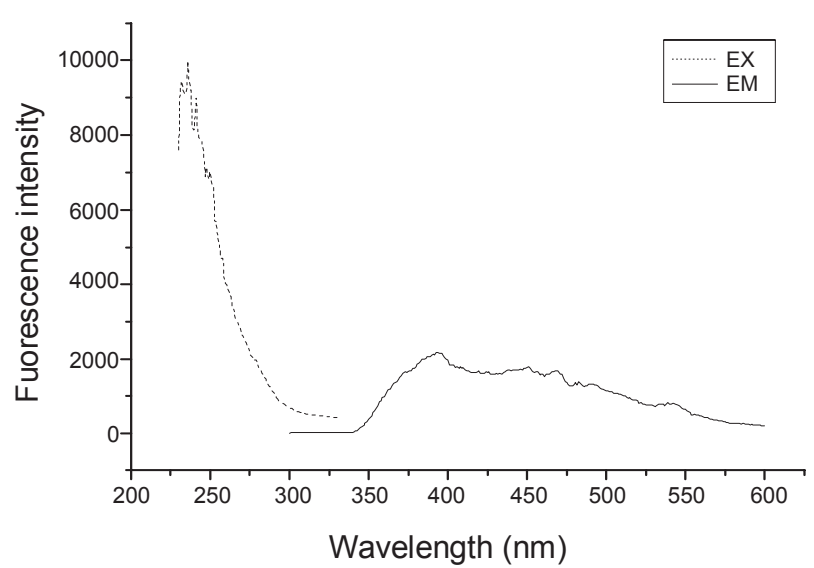

Figure 11. The excitation and emission spectrum of the Sm(III) complex.

of the ligand. The additional band in the $475-600 \mathrm{~nm}$ is phosphorescence of the ligand, due to a strong-spin orbit interaction of Gd(III). Finally, the luminescence of the Sm(III) complex corresponds to that of the ligand. The excitation band, peaking at $230 \mathrm{~nm}$, can be found in that of the ligand.

The luminescence of $\mathrm{Ln}(\mathrm{III})$ complexes is related to the efficiency of the intra-molecular energy transfer between the triplet energy states of the ligand and the emitting energy states of the metal ions. According to the fact that the observed luminescence intensity of the $\mathrm{Tb}$ (III) complex at $543 \mathrm{~nm}$ was much stronger than that of the $\mathrm{Eu}$ (III), Gd(III) and Sm(III) complexes, it can be inferred qualitatively that the energy difference between the ligand triplet states and the emitting energy state of $\mathrm{Tb}(\mathrm{III})$ is more favorable for energy transfer than those of the other three rare earth ions.

\section{Conclusion}

A novel fluorescent ligand and its lanthanide [Tb(III), Eu(III),
Gd(III) and Sm(III)] complexes have been synthesized. The TG-DTA and IR spectra of the free ligand and the metal complexes indicated that coordination of each of the four rare earth ions to the ligand was occurring at the nitrogen atoms and the oxygen atoms of the carbonyl. The study of their luminescence properties in solid state shows the Eu(III) and $\mathrm{Tb}(\mathrm{III})$ can be sensitized efficiently by the charge transfer from the ligand. Especially, the ligand is a more efficient antenna group for $\mathrm{Tb}$ (III) ions, since the $\mathrm{Tb}$ (III) complex only displayed characteristic metal-centered luminescence while ligand luminescence disappeared completely.

Acknowledgments. This project was supported by the China Postdoctoral Science Foundation (NO. 20080431027) and the Postdoctoral Science Foundation of Central South University.

\section{References}

1. Brunet, E.; Juanes, O.; Sedano, R.; Rodríguez-Ubis, J. C. Tetrahedron 2005, 61, 6757.

2. Buenzli, J. C. Acc. Chem. Res. 2006, 39, 53.

3. Nasso, I.; Galaup, C.; Havas, F.; Tisnes, P.; Picard, C.; Laurent, S.; Vander Elst, L.; Muller, R. Inorg. Chem. 2005, 44, 8293.

4. Dossing, A. Eur. J. Inorg. Chem. 2005, 1425.

5. Yuan, J.; Wang, G. Trends Anal. Chem. 2006, 25, 490.

6. Parker, D. Coord. Chem. Rev. 2000, 205, 109.

7. Arnesano, F.; Banci, L.; Bertini, I.; Capozzi, F.; Ciofi-Baffoni, S.; Ciurli, S.; Luchinat, C.; Mangani, S.; Rosato, A.; Turano, P.; Viezzoli, M. S. Coord. Chem. Rev. 2006, 250, 1419.

8. Kostova, I. Curr. Med. Chem.: Anti-Cancer Agents 2005, 5, 591.

9. Aime, S.; Geninatti Crich, S.; Gianolio, E.; Giovenzana, G. B.; Tei, L.; Terreno, E. Coord. Chem. Rev. 2006, 250, 1562.

10. Caravan, P. Chem. Soc. Rev. 2006, 35, 512.

11. Pandya, S.; Yu, J.; Parker, D. Dalton Trans. 2006, 2757.

12. Picard, C.; Geum, N.; Nasso, I.; Mestre, B.; Tisnes, P.; Laurent, S.; Muller, R. N.; Vander Elst, L. Bioorg. Med. Chem. Lett. 2006, 16, 5309.

13. Brunet, E.; Juanes, O.; Rodriguez-Ubis, J. C. Curr. Chem. Biol. 2007, 1, 11

14. Caravan, P.; Ellison, J. J.; McMurry, T. J.; Lauffer, R. B. Chem. Rev. 1999, 99, 2293.

15. Sammes, P. G.; Yahioglu, G. Nat. Prod. Rep. 1996, 13, 1.

16. Beer, P. D.; Brindley, G. D.; Fox, O. D.; Grieve, A.; Ogden, M. I.; Szemes, F.; Drew, M. G. B. J. Chem. Soc., Dalton Trans. 2002, 3101.

17. Picard, C.; Geum, N.; Nasso, I.; Mestre, B.; Tisnès, P.; Laurent, S.; Muller, R. N.; Elst, L. V. Bioorg. Med. Chem. Lett. 2006, 16, 5309.

18. Tang, R. R.; Yan, Z. E.; Guo, C. C. Chem. J. Chinese U. 2006, 27, 472.

19. Curtis, N. F.; Curtis, Y. M. Inorg. Chem. 1964, 4, 804.

20. Luo, Y. M.; L, J. L.; X, L. X.; T, R. R.; T, X. C. Spectrochim. Acta Part A 2009, 72, 703.

21. Shi, X. M.; Tang, R. R.; Gu, G. L.; Huang, K. L. Spectrochim. Acta Part A 2009, 72, 198.

22. Mukkala, V. M.; Sund, C.; Kwiatkowski, M. Helv. Chim. Acta 1992, 75.

23. Zhang, H. J.; Gou, R. H.; Yan, L.; Yang, R. D. Spectrochim. Acta Part A 2007, 66, 289. 